\title{
Determinants of successful completion of pulmonary rehabilitation in COPD
}

\author{
This article was published in the following Dove Press journal: \\ International Journal of COPD \\ 25 February 2016 \\ Number of times this article has been viewed
}

\author{
Angel T Brown' \\ Jason Hitchcock ${ }^{2}$ \\ Christopher Schumann ${ }^{2}$ \\ J Michael Wells ${ }^{1,3,4}$ \\ Mark T Dransfield ${ }^{1,3,4}$ \\ Surya $P$ Bhatt ${ }^{1,3}$ \\ 'Division of Pulmonary, Allergy, and \\ Critical Care Medicine, ${ }^{2}$ Department \\ of Cardiopulmonary Rehabilitation, \\ ${ }^{3} U A B$ Lung Health Center, University \\ of Alabama at Birmingham, ${ }^{4}$ Veterans \\ Affairs Medical Center, Birmingham, \\ AL, USA
}

Background: Despite known benefits, a significant proportion of patients with COPD do not complete pulmonary rehabilitation (PR). Little is known regarding which factors promote successful completion of PR.

Methods: We analyzed data from a prospectively maintained database of subjects with COPD who attended a PR program at the University of Alabama at Birmingham, from 1996 to 2013. Subjects were categorized as either completers or non-completers, based on successful completion of at least 8 weeks of PR. Demographics and comorbidities were recorded. Short Form 36 Health Survey, Beck Depression Inventory-II, and San Diego Shortness of Breath Questionnaire were administered to all participants at baseline and on completion of PR to assess participants' perception of their health status, severity of depression, and dyspnea with performance of activities of daily living. Univariate and multivariable analyses were performed to identify predictors of successful completion of PR.

Results: Four hundred and forty subjects were included, of whom 229 completed PR. Fortyone percent were female, and 17\% were African American. Compared with non-completers, completers had greater Short Form 36 Health Survey pain score, lower forced expiratory volume in the first second, and lower Beck Depression Inventory score, and included a lower percentage of current smokers. On multivariate analysis, cigarette smoking at enrollment was associated with lower likelihood of completion of PR (adjusted odds ratio $0.38,95 \%$ confidence interval $0.16-0.90 ; P=0.02)$.

Conclusion: Cigarette smoking was the sole independent predictor of PR dropout, and smoking cessation may warrant greater emphasis prior to enrollment.

Keywords: pulmonary rehabilitation, COPD, completion

\section{Introduction}

COPD is associated with significant morbidity and health care costs, and though current pharmacologic treatments have modest benefits, adjunctive pulmonary rehabilitation (PR) has been shown to substantially impact patient outcomes. ${ }^{1,2}$ The minimum recommended duration of therapy for PR is 8 weeks, and successful completion of PR is associated with improvements in quality of life and dyspnea, exercise tolerance, and a decrease in the rates of exacerbations and hospitalizations. ${ }^{3-5}$ Despite these benefits, recent studies have highlighted very poor referral rates for PR overall and as low as $10 \%$ post-hospitalization. ${ }^{6}$ Of those who do attend PR, a significant percentage of patients do not complete the program with attrition rates as high as $60 \% .^{7-9}$

The documented benefits of PR necessitate accurate identification of factors associated with non-completion. Prior studies have linked non-completion of PR to multiple factors including patients' perceptions of their illness and attitudes toward treatment options, time constraints, and transportation problems. ${ }^{10,11}$ In addition, while PR has
Correspondence: Surya P Bhatt Division of Pulmonary, Allergy, and Critical Care Medicine, University of Alabama at Birmingham, THT 422 1720, 2nd Avenue South, Birmingham AL 35294, USA Email spbhatt@uab.edu (c) (1) (5) 2016 Brown et al. This work is published and licensed by Dove Medical Press Limited. The full terms of this license are available at https://www.dovepress.com/terms.php
and incorporate the Creative Commons Attribution - Non Commercial (unported, v3.0) License (http:///creativecommons.org/licenses/by-nc/3.0/). By accessing the work you hereby accept the Terms. Non-commercial uses of the work are permitted without any further permission from Dove Medical Press Limited, provided the work is properly attributed. For permission for commercial use of this work, please see paragraphs 4.2 and 5 of our Terms (https://www.dovepress.com/terms.php). 
been shown to reduce the rate of exacerbation, one study found that individuals frequently withdrew or missed PR appointments due to COPD exacerbations or hospitalizations occurring during their enrolment. ${ }^{4,11}$

While previous smaller studies have documented socioeconomic and psychosocial factors associated with non-completion, many of these are not modifiable. In addition, prior reports have not adequately examined the impact of common COPD comorbidities on PR attendance. , $^{7,12-17}$ We analyzed data from a large, prospective cohort of COPD patients at a tertiary care hospital to systematically examine factors associated with PR attendance. Specifically, we hypothesized that several modifiable factors including smoking status as well as comorbid depression and anxiety would predict completion of PR. We also hypothesized that completion of PR at our center would result in improvements in exercise capacity and quality of life comparable to prior reports.

\section{Methods}

We analyzed data from a prospectively maintained database of patients who attended an outpatient PR program at the University of Alabama at Birmingham Hospital from January 1996 to April 2013. Subjects with a primary diagnosis of COPD (International Classification of Diseases Codes 491, 492, and 496) at the time of enrollment in PR were included. Those with other chronic respiratory diseases such as asthma, interstitial lung disease, and bronchiectasis, and patients who had lung transplantation were excluded. Baseline demographic data including smoking history, oxygen use, and comorbidities were obtained during the orientation visit prior to the initial PR session. Subjects were categorized as completers and non-completers, based on attendance and participation in two to three sessions per week for at least 8 consecutive weeks, completing 20 sessions. ${ }^{18}$

After obtaining written informed consent for enrollment in the PR database, questionnaires were administered to each participant, and these questionnaires were readministered at completion of PR. Dyspnea was assessed using the San Diego Shortness of Breath Questionnaire (SOBQ), a 24-question, self-administered questionnaire which rates dyspnea associated with activities of daily living; a change of five units in the SOBQ score is considered clinically significant (minimal clinically important difference, MCID). ${ }^{19}$ Health perception was assessed using the Short Form 36 Health Survey (SF-36) which has an MCID of 5.20,21 Depression was assessed using the Beck Depression Inventory (BDI)-II, a 21-question self-reported inventory for which higher total scores indicate more severe depression and a change of five is considered the MCID. ${ }^{22}$ Functional capacity was assessed using the 6-minute walk distance (6MWD) per American Thoracic Society guidelines. ${ }^{23}$ An MCID of $26 \mathrm{~m}$ was used for this study. ${ }^{24}$ Dyspnea after 6-minute walk test was assessed using the Rose Dyspnea Scale (range 0-4). ${ }^{25}$ Results of pulmonary function test performed within 2 years prior to enrollment were abstracted from medical records. Ethical approval for this analysis was obtained from the University of Alabama at Birmingham Institutional Review Board (assurance number FWA00005960).

PR sessions were determined by review of medical history, severity of disease, and walk test distance, and prescribed by an exercise physiologist. Subjects were administered two to three sessions per week for a maximum of 36 sessions (12 weeks). Exercise regimens were according to standard PR guidelines, and were supervised by certified clinical exercise physiologists. ${ }^{18}$ Exercise sessions included the following: aerobic exercises such as treadmill walking, cycle, and arm ergometry; resistance training such as machine weights, hand weights, and elastic bands; and breathing training techniques such as diaphragmatic breathing and pursed lips breathing. Regimens were individualized according to patients' baseline exercise tolerance as determined by initial 6MWD as well as their subjective sense of dyspnea. A multidisciplinary team of pulmonologists, respiratory therapists, dieticians, nurses, pharmacists, and exercise physiologists provided regular and scheduled education on various topics including understanding COPD, tobacco cessation counseling, respiratory medication use, nutrition, stress management, and oxygen therapy. Those who continued to smoke were allowed to participate in the program.

\section{Statistical analyses}

Univariate comparisons were made between PR completers and non-completers using chi-squared test for categorical variables, and two-tailed independent $t$-test for continuous variables. Variables significantly different between the two groups with an alpha of 0.10 were included in a multivariate logistic regression model to assess independent predictors of successful completion of PR. Paired $t$-test was used to assess impact of PR on measured outcomes such as SOBQ, SF-36, BDI, and 6MWD. $P$-value $<0.05$ was considered statistically significant. All analyses were performed using Statistical Package for the Social Sciences (version 22.0; SPSS Inc., Chicago, IL, USA). 


\section{Results}

Between 1996 and 2013, 440 subjects with COPD were enrolled in PR. Baseline demographics are presented in Table 1. Fifty-two (12\%) were current smokers, and $362(82 \%)$ were former smokers. Fifty-two (12\%) lived alone. Comorbidities are listed in Table 1, and 104 (23.6\%) had at least one comorbidity; 200 (45.4\%) and 284 (64.5\%) had at least two and three comorbidities, respectively.

Two hundred and twenty-nine (52\%) participants completed at least 8 weeks of PR. Completers underwent a median of 30 sessions (interquartile range 20-30), and non-completers had a median participation of seven sessions (interquartile range 3-11). Successful completion of PR was associated with a significant improvement in a number of measured variables (Table 2). 6MWD improved by 52 (73) $\mathrm{m}$ with $67 \%$ achieving MCID of $26 \mathrm{~m}$. Dyspnea post-6MWD also decreased (Rose Dyspnea Scale 1.2 \pm 1.2 vs
1.6 $\pm 1.2 ; P<0.001)$. SOBQ scores decreased by $10.5 \pm 16.1$, with $66 \%$ meeting MCID. BDI decreased by $3.5 \pm 6.9$ units, and average increase in almost all components of SF-36 was greater than the MCID (Table 2).

Tables 1 and 3 show a comparison of demographics and baseline functional indices at enrollment between completers and non-completers. There were no significant differences in age, sex, race, or body mass index, and the groups were evenly matched for indices of disease severity, comorbidities, and baseline functional capacity. Compared to completers, PR non-completers had greater degree of airflow obstruction (Table 1). As detailed in Table 1, the two groups were evenly matched with regard to comorbid conditions. There was also no difference in baseline 6MWD, SOBQ, SF-36, and BDI between the two groups (Table 3). Both groups were equally likely to be retired or not gainfully employed $(66.1 \%$ for completers vs $56.5 \%$ for non-completers; $P=0.23$ ). Compared

Table I Baseline demographics of entire cohort and of completers and non-completers of pulmonary rehabilitation

\begin{tabular}{|c|c|c|c|}
\hline & Overall $(n=440)$ & PR completers $(n=229)$ & PR non-completers $(n=2 \mid I)$ \\
\hline Age (years) & $66.2(9.0)$ & $66.5(9.0)$ & $65.8(9.1)$ \\
\hline Sex, female, n (\%) & I79 (4I) & 91 (39.7) & $88(4 \mid .7)$ \\
\hline \multicolumn{4}{|l|}{ Race } \\
\hline Caucasian & $317(72)$ & $165(72)$ & $152(72)$ \\
\hline African American & $76(17)$ & $42(18)$ & $34(16)$ \\
\hline Other & $47(I I)$ & $22(10)$ & $25(12)$ \\
\hline BMI $\left(\mathrm{m} / \mathrm{kg}^{2}\right)$ & $28.0(7.5)$ & $28.0(7.3)$ & $28.1(7.7)$ \\
\hline $\mathrm{FEV}_{1}(\mathrm{~L})^{\#, *}$ & $1.2(0.6)$ & $1.3(0.6)$ & I.I (0.6) \\
\hline $\mathrm{FEV}_{1} \%$ predicted ${ }^{\#}$ & $44.2(19.3)$ & $46.3(20.0)$ & $42.3(18.4)$ \\
\hline $\mathrm{FVC}(\mathrm{L})^{\#}$ & $2.5(0.9)$ & $2.4(0.9)$ & $2.6(0.9)$ \\
\hline Recent hospitalization, n (\%) & $178(40.5)$ & $88(34.4)$ & $90(42.7)$ \\
\hline \multicolumn{4}{|l|}{ Smoking status* } \\
\hline Current & $52(\mathrm{II} .8)$ & $16(7.0)$ & $36(17.3)$ \\
\hline Past & $362(82.3)$ & $197(86.8)$ & $165(79.3)$ \\
\hline Non & $21(4.8)$ & $14(6.2)$ & $7(3.4)$ \\
\hline Smoking pack years & $49.9(42.3)$ & $46.9(42.2)$ & $53.0(42.2)$ \\
\hline Home oxygen use, n (\%) & $220(50)$ & $117(5 \mathrm{I} .1)$ & $103(48.8)$ \\
\hline Comorbidity index & $2.2(1.6)$ & $2.1(1.5)$ & $2.3(1.6)$ \\
\hline Arthritis, n (\%) & $189(43)$ & $93(40.6)$ & $96(45.5)$ \\
\hline Coronary artery disease, $\mathrm{n}(\%)$ & 105 (23.9) & $59(25.8)$ & $46(21.8)$ \\
\hline Congestive heart failure, n (\%) & $46(10.5)$ & $26(11.4)$ & $20(9.5)$ \\
\hline Cerebrovascular disease, n (\%) & $34(7.7)$ & $15(6.6)$ & $19(9.0)$ \\
\hline Peripheral vascular disease, n (\%) & $44(10)$ & $24(10.5)$ & $20(9.5)$ \\
\hline Dementia, n (\%) & $10(2.3)$ & $3(1.3)$ & $7(3.3)$ \\
\hline Depression, n (\%) & 91 (20.7) & $46(20.1)$ & $45(21.3)$ \\
\hline Diabetes mellitus, n (\%) & $100(22.7)$ & $52(22.7)$ & $48(22.7)$ \\
\hline Hypertension, n (\%) & $277(63)$ & $|4|(6 \mid .6)$ & $136(64.5)$ \\
\hline Malignancy, n (\%) & $96(21.8)$ & $44(19.2)$ & $52(24.6)$ \\
\hline Obstructive sleep apnea, n (\%) & $50($ (II.4) & $29(12.7)$ & $10(2 \mathrm{I})$ \\
\hline
\end{tabular}

Notes: All values are expressed as mean (standard deviation) unless otherwise specified. \#Spirometry data available in 350 ( $80 \%$ ) patients within 2 years prior to enrollment. $* P<0.05$ for comparisons between completers and non-completers.

Abbreviations: PR, pulmonary rehabilitation; BMI, body mass index; $\mathrm{FEV}_{1}$, forced expiratory volume in the first second; FVC, forced vital capacity. 
Table 2 Comparison of functional indices pre- and postpulmonary rehabilitation for completers*

\begin{tabular}{|c|c|c|c|}
\hline Measurement & Pre & Post & $P$-value \\
\hline BDI & $12.0(8.4)$ & $8.4(6.8)$ & $<0.001$ \\
\hline 6MWD (m) & $296(109)$ & $348(111)$ & $<0.001$ \\
\hline SOBQ (units) & $59.6(22.4)$ & $49.2(23.2)$ & $<0.001$ \\
\hline SF-36 general health & $38.8(21.6)$ & $40.6(22.4)$ & 0.17 \\
\hline SF-36 physical functioning & $28.1(22.3)$ & $40.0(23.9)$ & $<0.001$ \\
\hline SF-36 physical role & $18.3(31.9)$ & $33.9(38.6)$ & $<0.001$ \\
\hline SF-36 emotional role & $56.7(43.9)$ & $70.7(38.8)$ & $<0.001$ \\
\hline SF-36 social functioning & $58.2(29.3)$ & $73.1(25.5)$ & $<0.001$ \\
\hline SF-36 mental health & $69.2(20.0)$ & $75.9(17.7)$ & $<0.001$ \\
\hline SF-36 pain & $65.1(27.3)$ & $69.2(24.9)$ & 0.01 \\
\hline SF-36 vitality & $36.0(19.3)$ & $48.6(20.6)$ & $<0.001$ \\
\hline
\end{tabular}

Notes: All values are expressed as mean (standard deviation). *We had full set of data for 227 of the 229 completers.

Abbreviations: BDI, Beck Depression Inventory; 6MWD, 6-minute walk distance; SOBQ, San Diego Shortness of Breath Questionnaire; SF-36, Short Form 36 Health Survey.

to completers, non-completers were no more likely to be dependent and live with their family (86.9\% vs $89.6 \%$; $P=0.39$ ). There was also no difference in the number of hospitalizations for acute exacerbation of COPD in the 6 months preceding study enrollment $(0.63 \pm 1.04$ in completers vs $0.81 \pm 1.31$ in non-completers; $P=0.11$ ). While there was no difference in overall smoking burden between the two groups, the number of current smokers at enrollment was lower in the PR completers compared to non-completers (7\% vs $17.3 \%$; $P=0.002$ ). Though only 16 smokers completed PR, we did not detect significant difference in benefits between smokers and nonsmokers who completed PR (data not shown).

Table 3 Comparison of baseline functional indices of entire cohort, and of completers and non-completers of pulmonary rehabilitation

\begin{tabular}{llll}
\hline Measurement & $\begin{array}{l}\text { Overall } \\
(\mathbf{n}=\mathbf{4 4 0})\end{array}$ & $\begin{array}{l}\text { PR } \\
\text { completers } \\
(\mathbf{n}=\mathbf{2 2 9})\end{array}$ & $\begin{array}{l}\text { PR non- } \\
\text { completers } \\
(\mathbf{n}=\mathbf{2 1} \text { I) }\end{array}$ \\
\hline BDI & $12.5(8.4)$ & II.7 (7.9) & I3.3 (8.9) \\
6MWD (m) & $275(114)$ & $280(106)$ & $269(122)$ \\
SOBQ (units) & $62.6(23.4)$ & $62.1(22.8)$ & $63.2(24.2)$ \\
SF-36 general health & $36.7(21.1)$ & $36.6(21.2)$ & $36.8(21.0)$ \\
SF-36 physical functioning & $25.7(21.5)$ & $25.5(21.5)$ & $25.8(21.5)$ \\
SF-36 physical role & $16.5(29.8)$ & $16.0(29.9)$ & $17.0(29.8)$ \\
SF-36 emotional role & $49.7(44.0)$ & $52.6(44.2)$ & $46.7(43.6)$ \\
SF-36 social functioning & $53.8(30.2)$ & $53.9(29.8)$ & $53.7(30.6)$ \\
SF-36 mental health & $67.3(20.4)$ & $68.5(19.8)$ & $66.0(21.0)$ \\
SF-36 pain* & $58.6(28.9)$ & $62.1(27.3)$ & $54.9(30.1)$ \\
SF-36 vitality & $33.7(20.3)$ & $34.4(19.2)$ & $32.9(21.4)$ \\
\hline
\end{tabular}

Notes: All values are expressed as mean (standard deviation). $* P<0.05$ for comparisons between completers and non-completers.

Abbreviations: PR, pulmonary rehabilitation; BDI, Beck Depression Inventory; 6MWD, 6-minute walk distance; SOBQ, San Diego Shortness of Breath Questionnaire; SF-36, Short Form 36 Health Survey.
Table 4 Independent predictors of completion of pulmonary rehabilitation

\begin{tabular}{lllll}
\hline Predictors & $\begin{array}{l}\text { Unadjusted } \\
\text { OR }\end{array}$ & $95 \% \mathbf{~ C l}$ & $\begin{array}{l}\text { Adjusted } \\
\text { OR }\end{array}$ & $95 \% \mathbf{~ C l}$ \\
\hline BDI & 0.98 & $0.95-1.0$ & 1.01 & $0.97-1.05$ \\
SF-36 pain & $1.009^{*}$ & $1.002-1.016$ & 1.01 & $0.99-1.02$ \\
FEV & $0.66^{*}$ & $0.47-0.95$ & 0.71 & $0.38-1.34$ \\
FVC & 0.81 & $0.64-1.03$ & 0.86 & $0.58-1.29$ \\
Current & $0.37^{* *}$ & $0.20-0.69$ & $0.38^{*}$ & $0.16-0.90$ \\
smoking status & & & & \\
\hline
\end{tabular}

Notes: $* P<0.05$. $* * P<0.01$.

Abbreviations: OR, odds ratio; $\mathrm{Cl}$, confidence interval; $\mathrm{BDI}$, Beck Depression Inventory; SF-36, Short Form 36 Health Survey; FEV , forced expiratory volume in the first second; FVC, forced vital capacity.

On bivariate regression, completion was more likely in those with higher SF-36 pain scores at baseline, greater $\mathrm{FEV}_{1}$, and lower rates of smoking at enrollment (Table 4). On multivariable analyses, cigarette smoking at enrollment was the sole predictor of completion of PR (adjusted odds ratio 0.38 , $95 \%$ confidence interval $0.16-0.90 ; P=0.02$ ) (Table 4 ).

\section{Discussion}

In this large prospective observational cohort, we found that close to half the subjects enrolled in PR did not complete therapy. The attrition rate for PR is very high despite the known benefits on quality of life, dyspnea, and exacerbation rates which are likely greater than those associated with existing pharmacotherapy., ${ }^{4,9}$ The drop-out rates are usually higher in real-world practice studies than for rehabilitation trials, and the rate of completion in our study is comparable to other large observational cohorts..$^{9,11,12}$ Completers showed significant improvements in multiple functional indices including exercise capacity, dyspnea scores, and quality of life. Cigarette smoking at enrollment was the sole independent risk factor for non-completion of PR.

While we hypothesized that underlying disease severity and comorbidities associated with COPD would predict completion of PR, we found that these factors were not independently associated with success. Lung function has not been shown to be a predictor of PR completion, except in the National Emphysema Treatment Trial which included patients with very severe COPD. ${ }^{9,26,27}$ Our findings also indicate that baseline lung function and functional capacity do not predict adherence to and completion of PR. We advance the literature by demonstrating that common COPD comorbidities also do not lead to dropout. While some studies have found baseline depression to be a predictor, a large study by Harrison et al found no association between depression and PR non-completion. . $^{12,14,15,28}$ While we demonstrated 
a benefit in depression scores with completion of PR, we did not find associations between completion and either physician-diagnosed depression or baseline BDI scores. The impact of level of baseline functional capacity, either objective or perceived, is controversial. While some studies reported that lower health status and baseline dyspnea predict non-completion, most studies including ours have not found this association. ${ }^{9,16,26}$ We did not find any association between some social factors such as living alone, dependency, and employment and non-completion, and the associations with social support, travel, living alone, and education status have been inconsistent in previous studies. $7,10,11,13,27,28$

We found that cigarette smoking at enrollment was the sole independent predictor of non-completion of PR. This appears to be the most consistently reported finding in previous studies. ${ }^{7,11,16,26,28-30}$ While cigarette smoking has been shown to result in skeletal muscle dysfunction, we did not find any interaction between continued cigarette smoking and change in 6MWD, making it unlikely that physical effects of continued smoking played a role in non-completion of PR. ${ }^{31}$ Cigarette smoking more likely represents high risk health behavior linked to negative health outcomes and a lower motivation to complete therapy. ${ }^{32}$ This link with continued smoking has been noted in other studies assessing adherence to medications and cardiac rehabilitation. ${ }^{33,34}$ Whether active smokers should be offered PR remains controversial as this is often perceived to be a marker of poor patient motivation and compliance, and some rehabilitation programs exclude active smokers despite evidence that rehabilitation benefits active smokers, a finding that was also seen in our study. ${ }^{35,36}$ Although few programs offer smoking cessation counseling as part of rehabilitation services, continued smoking has been shown to be associated with accelerated decline in composite disease indices, and thus, counseling might be an opportunity for targeted intervention, and to improve adherence to PR. ${ }^{29,35,36}$ Whether successful smoking cessation prior to or during rehabilitation improves adherence and benefit remains unknown.

Our study is unique for several reasons. Our study took place in an urban environment; we had a large sample size that included patients followed prospectively in a real-world setting without restrictive inclusion and exclusion criteria, thus accounting for multiple COPD comorbidities; we included current smokers; we included a significant number of women and African-American participants; and we used multiple validated questionnaires to assess baseline limitations that have been shown in previous studies to be important. Except for studies assessing the impact of depression, most studies that examined the question of predictors of completion were conducted outside the USA, and could be influenced by differences in health care delivery. Our study has some limitations. Despite being a large prospective study measuring multiple possible predictors, we could not measure numerous psychological and social factors that could be associated with non-completion such as travel, social support, income, and education. Although we documented non-completion, we did not record the reasons for dropout. We had data for change in the clinical outcome variables for only the completers, and the improvements seen in the various parameters have to be interpreted with caution as this was not the primary objective of the study.

\section{Conclusion}

Successful completion of PR results in improvement in exercise capacity, dyspnea, depression, and patient perception of their health status. Cigarette smoking was the sole independent predictor of unsuccessful completion of PR, and might represent a target for intervention prior to enrolment.

\section{Acknowledgments}

Some of the findings of this study were presented as an abstract at the American Thoracic Society Conference at San Diego in 2014. The abstract was published in the American Journal of Respiratory and Critical Care Medicine: American Thoracic Society International Conference Abstracts. American Thoracic Society; 2014:A2653-A. doi:10.1164/ ajrccm-conference.2014.189.1_MeetingAbstracts.A2653.

\section{Author contributions}

ATB contributed to study design, data collection, and manuscript writing. JH was involved in data collection, and reviewed the manuscript for important intellectual content. CS performed data collection, and reviewed the manuscript for important intellectual content. JMW performed data collection and reviewed the manuscript for important intellectual content. MTD contributed to manuscript writing, and reviewed the manuscript for important intellectual content. SPB was involved in study design, data collection, data analysis, and manuscript writing. He had full access to all of the data in the study and takes responsibility for the integrity of the data and the accuracy of the data analysis. All authors contributed toward data analysis, drafting and critically revising the paper and agree to be accountable for all aspects of the work.

\section{Disclosure}

Dr Brown, Mr Hitchcock, Dr Bhatt, and Mr Schumann have no conflicts of interest to declare. Dr Wells reports grants 
from the US National Institutes of Health/National Heart, Lung, and Blood Institute, research grants to his institution from GlaxoSmithKline and Forest, and consulting fees from AstraZeneca. Dr Dransfield reports grants from the NIH and the US Department of Defense, research funds for his institute from Pearl, Astra Zeneca, Novartis, Yungjin, Pulmonx, and PneumRx, and personal fees from GlaxoSmithKline, Boehringer Ingelheim, and Boston Scientific. All authors report no other conflicts of interest in this work.

\section{References}

1. Minino AM, Murphy SL, Xu J, Kochanek KD. Deaths: final data for 2008. Natl Vital Stat Rep. 2011;59:1-126.

2. Vestbo J, Hurd SS, Agusti AG, et al. Global strategy for the diagnosis, management, and prevention of chronic obstructive pulmonary disease: GOLD executive summary. Am J Respir Crit Care Med. 2013; 187:347-365.

3. McCarthy B, Casey D, Devane D, Murphy K, Murphy E, Lacasse Y. Pulmonary rehabilitation for chronic obstructive pulmonary disease. Cochrane Database Syst Rev. 2015;2:CD003793.

4. Puhan M, Scharplatz M, Troosters T, Walters EH, Steurer J. Pulmonary rehabilitation following exacerbations of chronic obstructive pulmonary disease. Cochrane Database Syst Rev. 2009:CD005305.

5. Spruit MA, Singh SJ, Garvey C, et al; ATS/ERS Taskforce on Pulmonary Rehabilitation. An official American Thoracic Society/European Respiratory Society statement: key concepts and advances in pulmonary rehabilitation. Am J Respir Crit Care Med. 2013;188:e13-e64.

6. Jones SE, Green SA, Clark AL, et al. Pulmonary rehabilitation following hospitalisation for acute exacerbation of COPD: referrals, uptake and adherence. Thorax. 2014;69:181-182.

7. Hayton C, Clark A, Olive S, et al. Barriers to pulmonary rehabilitation: characteristics that predict patient attendance and adherence. Respir Med. 2013;107:401-407.

8. Boutou AK, Tanner RJ, Lord VM, et al. An evaluation of factors associated with completion and benefit from pulmonary rehabilitation in COPD. BMJ Open Respir Res. 2014;1:e00051.

9. Hogg L, Garrod R, Thornton H, McDonnell L, Bellas H, White P. Effectiveness, attendance, and completion of an integrated, system-wide pulmonary rehabilitation service for COPD: prospective observational study. COPD. 2012;9:546-554.

10. Keating A, Lee A, Holland AE. What prevents people with chronic obstructive pulmonary disease from attending pulmonary rehabilitation? A systematic review. Chron Respir Dis. 2011;8:89-99.

11. Fischer MJ, Scharloo M, Abbink JJ, et al. Drop-out and attendance in pulmonary rehabilitation: the role of clinical and psychosocial variables. Respir Med. 2009;103:1564-1571.

12. Tselebis A, Kosmas E, Bratis D, et al. Contribution of psychological factors in dropping out from chronic obstructive pulmonary disease rehabilitation programs. BioMed Res Int. 2014;2014:401326.

13. Arnold E, Bruton A, Ellis-Hill C. Adherence to pulmonary rehabilitation: a qualitative study. Respir Med. 2006;100:1716-1723.

14. Garrod R, Marshall J, Barley E, Jones PW. Predictors of success and failure in pulmonary rehabilitation. Eur Respir J. 2006;27:788-794.

15. Harrison SL, Greening NJ, Williams JE, Morgan MD, Steiner MC, Singh SJ. Have we underestimated the efficacy of pulmonary rehabilitation in improving mood? Respir Med. 2012;106:838-844.

16. Sabit R, Griffiths TL, Watkins AJ, et al. Predictors of poor attendance at an outpatient pulmonary rehabilitation programme. Respir Med. 2008;102: 819-824.
17. Bhatt SP, Dransfield MT. Chronic obstructive pulmonary disease and cardiovascular disease. Transl Res. 2013;162:237-251.

18. Nici L, Donner C, Wouters E, et al; ATS/ERS Pulmonary Rehabilitation Writing Committee. American Thoracic Society/European Respiratory Society statement on pulmonary rehabilitation. Am J Respir Crit Care Med. 2006;173:1390-1413.

19. Kupferberg DH, Kaplan RM, Slymen DJ, Ries AL. Minimal clinically important difference for the UCSD Shortness of Breath Questionnaire. J Cardiopulm Rehabil. 2005;25:370-377.

20. Ware JE Jr, Sherbourne CD. The MOS 36-item short-form health survey (SF-36). I. Conceptual framework and item selection. Med Care. 1992;30:473-483.

21. Mahler DA, Mackowiak JI. Evaluation of the short-form 36-item questionnaire to measure health-related quality of life in patients with COPD. Chest. 1995;107:1585-1589.

22. Hiroe T, Kojima M, Yamamoto I, et al. Gradations of clinical severity and sensitivity to change assessed with the Beck Depression Inventory-II in Japanese patients with depression. Psychiatry Res. 2005; 135:229-235.

23. ATS Committee on Proficiency Standards for Clinical Pulmonary Function Laboratories. ATS statement: guidelines for the six-minute walk test. Am J Respir Crit Care Med. 2002;166:111-117.

24. Puhan MA, Chandra D, Mosenifar Z, et al; National Emphysema Treatment Trial (NETT) Research Group. The minimal important difference of exercise tests in severe COPD. Eur Respir J. 2011;37:784-790.

25. Rose GA, Blackburn H. Cardiovascular survey methods. Monogr Ser World Health Organ. 1968;56:1-188.

26. Selzler AM, Simmonds L, Rodgers WM, Wong EY, Stickland MK. Pulmonary rehabilitation in chronic obstructive pulmonary disease: predictors of program completion and success. COPD. 2012;9:538-545.

27. Fan VS, Giardino ND, Blough DK, Kaplan RM, Ramsey SD; Nett Research Group. Costs of pulmonary rehabilitation and predictors of adherence in the National Emphysema Treatment Trial. COPD. 2008;5: 105-116.

28. Young P, Dewse M, Fergusson W, Kolbe J. Respiratory rehabilitation in chronic obstructive pulmonary disease: predictors of nonadherence. Eur Respir J. 1999;13:855-859.

29. Cote CG, Celli BR. Pulmonary rehabilitation and the BODE index in COPD. Eur Respir J. 2005;26:630-636.

30. Cassidy S, Turnbull S, Gardani M, Kirkwood K. Attendance at pulmonary rehabilitation classes: an exploration of demographic, physiological and psychological factors that predict completion of treatment. Chron Respir Dis. 2014;11:95-102.

31. Degens H, Gayan-Ramirez G, van Hees HW. Smoking-induced skeletal muscle dysfunction: from evidence to mechanisms. Am J Respir Crit Care Med. 2015;191:620-625.

32. Bethea J, Murtagh B, Wallace SE. "I don't mind damaging my own body" a qualitative study of the factors that motivate smokers to quit. BMC Public Health. 2015;15:4

33. Shea S, Misra D, Ehrlich MH, Field L, Francis CK. Correlates of nonadherence to hypertension treatment in an inner-city minority population. Am J Public Health. 1992;82:1607-1612.

34. Gaalema DE, Cutler AY, Higgins ST, Ades PA. Smoking and cardiac rehabilitation participation: associations with referral, attendance and adherence. Prev Med. 2015;80:67-74.

35. Brooks D, Lacasse Y, Goldstein RS. Pulmonary rehabilitation programs in Canada: national survey. Can Respir J. 1999;6:55-63.

36. Bickford LS, Hodgkin JE, McInturff SL. National pulmonary rehabilitation survey. Update. J Cardiopulm Rehabil. 1995;15:406-411. 
International Journal of COPD

\section{Publish your work in this journal}

The International Journal of COPD is an international, peer-reviewed journal of therapeutics and pharmacology focusing on concise rapid reporting of clinical studies and reviews in COPD. Special focus is given to the pathophysiological processes underlying the disease, intervention programs, patient focused education, and self management protocols.

This journal is indexed on PubMed Central, MedLine and CAS. The manuscript management system is completely online and includes a very quick and fair peer-review system, which is all easy to use. Visit http://www.dovepress.com/testimonials.php to read real quotes from published authors 